\title{
Bilateral Exchange Rates and Jobs
}

\author{
Eddy Bekkers and Joseph Francois*
}

\begin{abstract}
We study the labor market effects of realignment in fixed bilateral exchange rates, such as China's peg to the US dollar. We employ the open economy model by de Melo and Robinson to identify the core parameters of the real, trade side of the economy driving the unemployment effects of bilateral exchange rate realignment. A small open economy version of the model is explored analytically and a large multicountry version numerically. Analytics in the small open economy model show that unemployment effects of adjusting of a bilateral peg hinge on the fraction exported to and imported from the trading partner. A larger fraction exported to and a smaller fraction imported from the trading partner make it more likely that revaluation of a trading partner's currency has beneficial effects. Numerics in the large economy model show that Chinese revaluation can generate both positive and negative unemployment effects depending upon underlying parameter values. Adverse unemployment effects can go along with an improving trade balance.
\end{abstract}

\section{Introduction}

The recent exchange rate literature is largely focused on monetary policy and credit imbalances. Yet with bilateral pegs (such as East Asian economies relative to the US dollar) policy focus has also been placed on relative real prices and export competitiveness rather than monetary policy per se. Indeed bilateral pegs and fixed exchange rates have been a source of significant tension within the multilateral trading system. Most recently, this has been reflected in real pressure in the USA for punitive tariffs against China, backed by Krugman's claims that in recent years China's currency peg to the US dollar has cost the USA millions of jobs. ${ }^{1}$ Earlier iterations of the political cycle around bilateral rates include the older literature on Japan and US competitiveness, including Krugman (1991).

While bilateral exchange rates are highly policy relevant, broadly speaking the literature is focused instead on generic exchange rate changes (i.e. vis- $\grave{a}$-vis the world as a whole), and the role of interest rates and monetary policy in a world of floating rates. The literature on China's misalignment has focused on the magnitude of the misalignment and its impact on China's export performance. ${ }^{2}$ This paper's contribution is a better understanding of the real-side effects of fixed bilateral exchange rate pegs and undervaluation. While we explore the Chinese case numerically, we also provide a more general analytical assessment of the issue. We examine the traderelated impact of exchange rate policies, focusing on the impact of a bilateral peg on real price competitiveness and unemployment. At a practical level, the issue of bilateral revaluation has immediate relevance for trade policy given the exchange rates dispute between China and the USA, the earlier exchange rates dispute between

\footnotetext{
* Bekkers: Department of Economics, Johannes Kepler University of Linz, Altenbergerstr 69, 4040 Linz, Austria. E-mail: eddy.bekkers@jku.at. Francois: University of Bern, Switzerland and CEPR, London, UK. We would like to thank Richard Baldwin, Peter Egger, Doug Nelson, Clint Shiells, a set of anonymous referees, and participants at CEPR workshops and ETSG sessions for helpful comments and suggestions.
} 
Japan and the USA and ongoing calls by Brazil for inclusion of exchange rate issues within the trading system's governing body of the World Trade Organization (WTO).

As we are interested in trade related mechanics, we work with an analytical general equilibrium model of production and trade rather than a dynamic stochastic general equilibrium (DSGE) model. More specifically, we employ the open economy general equilibrium model of de Melo and Robinson (1989) to study the unemployment effects of bilateral realignment of exchange rates. We first study a small open economy version of the model to derive analytical results and then use numerics to explore bilateral realignment in a setting with multiple, large countries.

In the small open economy model of de Melo and Robinson (1989) goods are produced for the domestic and the exporting market. Domestic and exporting goods are imperfect substitutes. Consumption consists of domestic goods and imports, which are also imperfect substitutes. The economy is small, implying that it does not affect world prices. We add the use of intermediates in production besides capital and labor and work with Armington preferences across goods from different trading partners. The labor market is characterized by efficiency wages implying that unemployment emerges endogenously in the model. We focus on an environment of fixed exchange rates and consider the effect of realignments of the exchange rate that is under direct control of the policymaker of a country's trading partner. So, we do not model the endogenous determination of the exchange rate. ${ }^{3}$ Also, with the focus on the real side of the economy, we do not model trade in financial assets explicitly. We work with a setup where the Marshall-Lerner condition is satisfied, implying that the trade balance improves in response to revaluation of a trading partner.

The followed approach enables us for the small open economy case to identify analytically and in an intuitive way the core parameters of the real side of the economy driving the unemployment effects of bilateral realignment. To build intuition we look at the case of currency revaluation of a country's trading partner, fitting with the example of the unemployment effect in the USA of China revaluing its currency. We show that the import and export shares of trade of the exchange rate realigning trade partner are crucial determinants of the unemployment effects. Conventional reasoning suggests that a country's output and employment will rise when its currency falls. The chain of logic is relatively straightforward-improved export competitiveness stimulates demand and so drives up output. The increased price of imports as a result of devaluation may also reduce output through adverse supply effects (Edwards, 1986; van Wijnbergen, 1986). ${ }^{4}$ We show in a baseline model with flexible labor markets and balanced trade that a trading partner's currency revaluation is harmful when the import share from that country exceeds the export share to that country. In the analytics we also show the impact of imperfect information, incomplete exchange rate pass-through and the share of intermediates in gross output on the unemployment effects of bilateral revaluation.

To study bilateral realignment in a setting with multiple, large countries we move on to numerics. The numeric version of the model is calibrated to global macroeconomic data in 2007 aggregated to 19 economic regions using macroeconomic data from the IMF's World Economic Outlook and trade data from the GTAPv8 database. We explore the effects of a $20 \%$ revaluation of the Chinese exchange rate. We consider both a bilateral revaluation vis-à-vis the dollar and a multilateral revaluation vis$\grave{a}$-vis all other currencies. The numerics generate three interesting sets of results. First, calibration to real world data shows that the unemployment effects of Chinese revaluation in the USA can be both positive and negative depending upon underlying parameter values. A possible unemployment increasing effect is driven by the fact that 
the import share of China in total imports of the USA $(16 \%$ in 2007) is much larger than the export share of China in US exports (5\% in 2007). Second, we demonstrate that the increasing unemployment effects of a trading partner's exchange rate revaluation can go along with an improving trade balance. So, revaluation of the Chinese currency can lead to a higher US unemployment and still generate an improving trade balance for the USA. Third, numerics highlight the importance of the different parameters in the model for the unemployment effects of bilateral realignment. A larger exchange rate pass-through makes it more likely that Chinese revaluation leads to a higher US unemployment rate. A smaller wage curve elasticity and a larger input substitution elasticity magnify the effect of Chinese revaluation, i.e. they lead to a stronger positive or negative reaction in the US unemployment rate. The import substitution and export transformation elasticities have an ambiguous effect on the unemployment effects of Chinese revaluation.

Work related to the current paper consists of three strands of literature. First, there is the literature pointing out the various theoretical channels through which broadbased devaluations can be contractionary (Hirschman, 1949; Diaz-Alejandro, 1963; Krugman and Taylor, 1978; Edwards, 1986; van Wijnbergen, 1986). Devaluations can have contractionary effects through the supply side because of increased prices of imported intermediates and upward wage pressure. This is the channel stressed in the current paper. Other possible contractionary effects run through the demand side as a result of a change in the composition of demand and reduced tariff revenues (Diaz-Alejandro, 1963; Krugman and Taylor, 1978) and through balance sheet effects with firms' borrowing costs of foreign denominated loans rising with currency devaluations (Cespedes et al. 2004; Frankel, 2005). ${ }^{5}$

A second related strand of literature consists of the theoretical open economy New Keynesian models and the open economy DSGE models that can be used in real world simulations. Gali and Monacelli (2005) develop a small open economy New Keynesian model and compare the welfare effects of an exchange rate peg with other policy rules such as domestic inflation and consumer price index (CPI)-based Taylor rules concluding that the latter rules dominate the exchange rate peg in welfare terms. Open economy DSGE models such as Erceg et al. (2006), Adolfson et al. (2007) and Bodenstein et al. (2009) can be used to study the effects of exchange rate realignments. These models do not consider fixed exchange rate regimes, so shocks to monetary policy leading to changes in the exchange rate can be employed in these models to evaluate the effects of exchange rate changes.

A third related strand of literature is the empirical work evaluating the unemployment effects of devaluations using a variety of methods (Edwards, 1986; Gylfason and Radetzki, 1991; Kamin and John, 2000; Shi, 2006; Bebczuk et al., 2006). Most of this work finds that devaluations work out contractionary. All cited work in the three strands of literature explores the impact of broad based revaluation vis-à-vis all trading partners, whereas our focus is the impact of revaluation of one of the trading partners. One exception is the work by Fair (2010). He uses a macroeconometric model to estimate the effects of Chinese realignment and finds that output and employment fall slightly with a Chinese revaluation. Fair (2010) also stresses the adverse effect through higher import prices, but he does not identify trade shares as a crucial variable and focuses on wealth and interest rate effects of higher import prices instead of effects through prices of intermediates and wage demands.

The paper is organized as follows. We develop the basic model in section 2 . The properties of the small open economy model are explored analytically in section 3 . 
This is followed by the multicountry numerics in section 4. Finally, we summarize and conclude in section 5 .

\section{Basic Model}

A small open economy produces and consumes tradables and non tradables. Output $X$ is a constant elasticity of transformation (CET) function of the imperfect substitutes domestic goods supplied, $D_{s}$, and exports, $E:^{6}$

$$
X=G\left(E, D_{s}\right)=\left(\beta_{E} E^{\frac{\theta+1}{\theta}}+\beta_{D_{s}} D_{s}^{\frac{\theta+1}{\theta}}\right)^{\frac{\theta}{\theta+1}}
$$

Consumption $Q$ is a constant elasticity of substitution (CES) function of the imperfect substitutes domestic goods demanded, $D_{d}$, and imports, $M$ :

$$
Q=F\left(M, D_{d}\right)=\left(\alpha_{M} M^{\frac{\sigma-1}{\sigma}}+\alpha_{D_{d}} D_{d}^{\frac{\sigma-1}{\sigma}}\right)^{\frac{\sigma}{\sigma-1}} .
$$

The price indexes $p_{x}$ and $p_{q}$ corresponding respectively to $X$ and $Q$ in (1) and (2) are a function of the aggregate exporting price $p_{e}$, the aggregate importing price $p_{m}$ and the domestic price $p_{d}$ :

$$
\begin{aligned}
& p_{x}=\left(\beta_{E}^{-\theta} p_{e}^{\theta+1}+\beta_{D_{s}}^{-\theta} p_{d}^{\theta+1}\right)^{\frac{1}{\theta+1}} \\
& p_{q}=\left(\alpha_{M}^{\sigma} p_{m}^{1-\sigma}+\alpha_{D_{d}}^{\sigma} p_{d}^{1-\sigma}\right)^{\frac{1}{1-\sigma}} .
\end{aligned}
$$

Optimality along the CET transformation curve and the CES indifference curve imply the following conditions:

$$
\begin{aligned}
& \frac{E}{D_{s}}=\left(\frac{\beta_{D_{s}}}{\beta_{E}} \frac{p_{e}}{p_{d}}\right)^{\theta}, \\
& \frac{M}{D_{d}}=\left(\frac{\alpha_{M}}{\alpha_{D_{d}}} \frac{p_{d}}{p_{m}}\right)^{\sigma} .
\end{aligned}
$$

Domestic equilibrium requires equality of supply and demand for nontradables:

$$
D_{d}-D_{s}=0 \text {. }
$$

There are $N$ trade partners. With Armington preferences the price index of imports $p_{m}$ and the price index of exports $p_{e}$ are equal to:

$$
\begin{aligned}
& p_{m}=\left(\sum_{i=1}^{N} \gamma_{i}^{\eta} p_{m, i}^{1-\eta}\right)^{\frac{1}{1-\eta}} \\
& p_{e}=\left(\sum_{i=1}^{N} \delta_{i}^{-\omega} p_{e, i}^{\omega+1}\right)^{\frac{1}{\omega+1}},
\end{aligned}
$$


$p_{m, i}$ and $p_{e, i}$ are respectively the import prices and export prices of country $i$ in terms of the home currency. Import prices $\pi_{m, i}$ and export prices $\pi_{e, i}$ in terms of the currency of country $i$ are given reflecting the small country assumption. The prices in terms of the home currency and country's $i$ currency are related by a bilateral exchange rate $R_{i}$, defined as the price of the currency of country $i$ in terms of the home currency: ${ }^{7}$

$$
\begin{aligned}
& p_{m, i}=R_{i} \pi_{m, i}, \\
& p_{e, i}=R_{i} \pi_{e, i} .
\end{aligned}
$$

An increase in $R_{i}$ corresponds with a revaluation of the exchange rate of trading partner $i$. Capital inflows $B$ are positive when the country's imports exceed its exports:

$$
B=p_{m} M-p_{e} E
$$

To address both demand and supply side effects, we add a production structure, in contrast to de Melo and Robinson (1989) where output $X$ is fixed. There is a continuum of firms of mass $N$, using intermediates $I$, labor $L$ and capital $K$ in production giving rise to the following CES production function:

$$
X=\left(\lambda_{I} I^{\frac{\rho-1}{\rho}}+\lambda_{L} L^{\frac{\rho-1}{\rho}}+\lambda_{K} K^{\frac{\rho-1}{\rho}}\right)^{\frac{\rho}{\rho-1}}
$$

We assume that the amount of capital is fixed. Firms use aggregate good $Q$ with corresponding price $p_{q}$ as intermediate inputs implying the following demand for intermediates:

$$
I=\left(\lambda_{I} \frac{p_{x}}{p_{q}}\right)^{\rho} X
$$

The labor market is characterized by efficiency wages as in Shapiro and Stiglitz (1984). We follow the exposition of the model in Boeters and Savard (2013), which is based upon Pissarides (1998). There is a continuum of workers of mass $\bar{L}$ either employed or unemployed. Workers can choose between two effort levels, an effort level of 0 and an effort level of $e$. Firms will pay high enough wages to induce the positive effort level $e$ and hence prevent shirking. With $s$ the separation rate, so the hazard rate at which a job ends, $\chi$ the hazard rate at which a shirking worker gets caught, $d$ the discount rate of workers, $w$ the nominal wage and $c$ the replacement rate (level of unemployment benefits relative to real wages), the no-shirking condition can be written as:

$$
\frac{w}{p_{q}}=\frac{1}{1-c}\left(d+\chi+\frac{s}{u}\right) \frac{e}{\chi},
$$

$u$ is the unemployment rate and is defined as:

$$
u=\frac{\bar{L}-L}{\bar{L}} \text {. }
$$


Labor demand follows from profit maximization and is given by the following expression:

$$
L=\left(\phi_{L} \frac{p_{x}}{w}\right)^{\rho} X
$$

\section{Small Open Economy Model: Analytics}

In this section we point out analytical results on the unemployment effects of exchange rate realignment of one of the trading partners in a small economy setting starting from balanced trade, i.e. $B=0$. We can log linearize the equilibrium conditions in section 2 to derive the effect of a change in the exchange rate of country $i, R_{i}$ on the unemployment rate $u$. As shown in the Appendix this generates the following relative change in unemployment:

$$
\hat{u}=\frac{\rho}{A(u)} \frac{1}{1-\lambda_{I}-\lambda_{L}} \kappa_{T R}\left(s_{m, i}-s_{e, i}\right) \widehat{R}_{i} .
$$

Variables with a hat indicate relative changes. $\kappa_{T R}$ is the trade share of output, $\kappa_{T R}=\frac{p_{e} E}{p_{e} E+p_{d} D}$ and is equal on the import and export side, since $B=0 . s_{m, i}$ and $s_{e, i}$ are the import and export share of country $i$ in total imports and total exports respectively, $s_{m, i}=\frac{p_{m, i} M_{i}}{\sum_{i=1}^{N} p_{m, i} M_{i}}$ and $s_{e, i}=\frac{p_{e, i} E_{i}}{\sum_{i=1}^{N} p_{e, i} E_{i}} . A(u)$ is defined in the Appendix. It is positive and is a function of the unemployment rate and the parameters of the model.

We can state the following result based upon equation (18):

Proposition 1. In a small economy starting from balanced trade, the unemployment rate falls in response to revaluation of the currency of one of its trading partners if and only if the share of its exports to the trading partner is larger than the share of imports from the trading partner.

Proposition 1 follows directly from (18). The unemployment rate is affected through three channels by a revaluation of the currency of one of its trading partners. First, an increase in the sales price $p_{x}$ as a result of revaluation of the currency of a trading partner raises the value marginal product of labor stimulating labor demand. Second, an increase in $p_{q}$ raises the cost of intermediates used in production. This decreases the marginal product of labor and thus the demand for labor. Third, the rise in $p_{q}$ raises the wage demanded by workers, which leads to a higher unemployment rate. Under the assumptions of a small economy starting from balanced trade, the beneficial effect of a revaluation of a trading partner's currency dominates if the export share of the revaluating trading partner is larger than the import share.

As a next step we explore the impact of two types of rigidities on the unemployment effect of exchange rate realignment of a country's trading partner that might play a role in the short run. In particular, we study the impact of imperfect information on the labor market and of incomplete pass-through in the exchange rate market. The role of imperfect information in the macro literature is discussed by Mankiw and 
Reis $(2002$, 2010). We introduce imperfect information on the labor market with workers demanding compensation for the expected instead of actual price level and partial adjustment of the expected price level to the actual price level. Campbell (2010) chooses the same setup by merging efficiency wages with partial adjustment of the expected price level. Partial adjustment of the expected price level is most appropriate in a dynamic setting like Campbell (2010) who derives a Philips curve with his setup. But also in our static setup it can be employed. Movement from one equilibrium to the next with partial adjustment of expected prices represents a movement in the medium run, where workers do not ask full compensation for increased prices. It can be seen as the intermediate case between the short run, where wages would be fixed and the long run where wages fully adjust requiring full compensation for price increases.

To model imperfect information we replace the actual real wage $\frac{w}{p_{q}}$ on the lefthand side of the no shirking condition in (15) by the expected real wage $\frac{w}{p_{q}^{e}}$ with $p_{q}^{e}$ the expected price level. The expected price level $p_{q}^{e}$ responds less than proportional to the true price level $p_{q}, \widehat{p_{q}^{e}}=\xi_{p_{q}} \widehat{p_{q}}$, with $\xi_{p_{q}}$ an inverse measure for the degree of imperfect information.

In the short run, changes in exchange rates might not fully work through into domestic prices. $^{8}$ The literature on exchange rate pass-through documents a rate of pass-through much lower than 1 (see, e.g. Gopinath and Rigobon, 2008; Nakamura and Steinsson, 2012). Working with a small country, there can be imperfect exchange rate pass-through on the importer side. The domestic import price $p_{m, i}$ changes less than proportional with the exchange rate $R_{i}, \widehat{p_{m, i}}=\xi_{p_{m, i}} \widehat{R_{i}}$, with $\xi_{p_{m, i}}$ a measure for the degree of pass-through of goods from country $i$.

Adding imperfect information and incomplete exchange rate pass-through, the new expression for the change in unemployment is: ${ }^{9}$

$$
\begin{aligned}
\hat{u}= & \frac{\rho}{A(u)} \frac{\kappa_{T R}}{1-\lambda_{I}-\lambda_{L}}\left(\left(\lambda_{I}+\xi_{p_{q}}\left(1-\lambda_{I}\right)\right) s_{m, i} \xi_{p_{m, i}}-s_{e, i}\right) \widehat{R}_{i} \\
& +\frac{\rho}{A(u)} \frac{\left(1-\kappa_{T R}\right)}{1-\lambda_{I}-\lambda_{L}}\left(\lambda_{I}+\xi_{p_{q}}\left(1-\lambda_{I}\right)-1\right)\left(A_{2} \widehat{R_{i}}+\frac{1}{\theta+\sigma} d B\right) .
\end{aligned}
$$

$A_{2}$ is defined in the Appendix. It is positive and a function of parameters. Equation (19) makes clear that the export share and import share of a trading partner, the extent of incomplete information as measured by the parameter $\xi_{p q}$, the pass-through rate $\xi_{p_{m, i}}$ and the intermediates share of total input $\lambda_{I}$ together determine the unemployment effect of a trading partner's revaluation. ${ }^{10}$ More specific we can state the following:

Proposition 2. In a small economy with balanced trade and a substitution elasticity between domestic and imported goods larger than 1, it is more likely that revaluation of the currency of one of the trading partners of a country drives down the unemployment rate of a country if:

1. The degree of imperfect information among workers is larger;

2. The rate of exchange rate pass-through is smaller;

3. The share of intermediates in total input is smaller. 
The first part of Proposition 2 reflects that a larger degree of imperfect information means that higher import prices do not have such a big impact on wages the workers demand. This reduces the adverse effect on unemployment of revaluation of a trading partner. ${ }^{11}$ Hence, the unemployment effect is more likely to be detrimental in the longer run, when wages can fully adjust.

Incomplete pass-through goes together with markup adjustments and market power. With revaluation of the currency of a trading partner, incomplete pass-through means that importers with market power lower their markups. Part 2 points out that a lower degree of pass-through dampens the adverse unemployment effects of revaluation of the currency of a trading partner, because import prices do not rise so much. The importers with market power like for example Walmart pay the price for this dampened effect on unemployment, because of the lower markups they charge. ${ }^{12}$

The third part is driven by the fact that a larger import price raises unemployment through two channels: it depresses the marginal product of labor and raises wage demands. With labor market rigidities, the impact through the first channel is stronger. Hence, the larger the intermediates share, the larger the detrimental effect on unemployment. ${ }^{13}$

\section{Large Economy Model: Numerics}

So far we have worked with a small country to derive analytical results. In this section, we work with a large country setting and thus move to numerics. The model is calibrated to macroeconomic data for 2007 aggregated to 19 economic regions, based on aggregate data from the IMF's World Economic Outlook database (IMF, 2010), trade data from the Global Trade Analysis Project (GTAP)v8 database (Hertel et al., 2012) and unemployment rates from the International Labour Organization (ILO) (ILO, 2012). The Appendix lists the set of equations for the multicountry model. All equations are as in the basic model, but we explicitly model all countries, implying that foreign prices are not given. ${ }^{14}$ Running simulations requires an explicit expression for how the capital balance changes. We focus on the case where the Marshall-Lerner condition is met (so trade balances improve with a devalued exchange rate.) These conditions are discussed formally in the Appendix.

In the numerical analysis we have to choose values for the parameters $\sigma, \eta, \theta, \omega, \rho$, $c, d, \chi, s, e, \mu, \xi_{p_{q}}, \xi_{p_{m}}$. The chosen values and the sources used are displayed in Table 1 . We start with a discussion of the trade elasticities. The substitution elasticities on the importer side $\sigma$ and $\eta$ are taken from Feenstra et al. (2012) who argue that the "macro" elasticity between domestic and imported varieties is smaller than the "micro" elasticity between imported varieties from different sources. Their median estimates are a macro elasticity of $\sigma$ not different from 1 and a micro elasticity $\eta$ equal to 3.1. For the transformation elasticities $\theta$ and $\omega$ we use Hillberry and Hummels (2013) who relate the transformation elasticities to the substitution elasticity and Pareto shape parameter in a Melitz (2003) firm heterogeneity model. The argument is based on Feenstra (2010) who shows that the Melitz (2003) model implies a CET function for exports to different destinations. In particular, the transformation elasticity is equal to $\frac{\alpha l}{l-1}-1$, with $a$ the Pareto shape parameter and $\imath$ the substitution elasticity between varieties. Using the values for the substitution elasticity of 3.8 and the shape parameter of 3.4 from Bernard et al. (2007), we set the transformation elasticities $\theta$ and $\omega$ at 3.6. ${ }^{15}$ 
Table 1. Baseline Parameters

\begin{tabular}{|c|c|c|c|}
\hline Parameter & Value & Description & Source \\
\hline$\sigma$ & 1 & $\begin{array}{c}\text { Substitution elasticity between } \\
\text { domestic goods and imports }\end{array}$ & Feenstra et al. (2012) \\
\hline$\eta$ & 3.1 & $\begin{array}{l}\text { Substitution elasticity between } \\
\text { imports different countries }\end{array}$ & Feenstra et al. (2012) \\
\hline$\theta$ & 3.6 & $\begin{array}{l}\text { Transformation elasticity } \\
\text { between domestic goods and } \\
\text { exports }\end{array}$ & $\begin{array}{l}\text { Hillberry and Hummels (2013) } \\
\text { and Bernard et al. (2007) }\end{array}$ \\
\hline$\omega$ & 3.6 & $\begin{array}{l}\text { Transformation elasticity } \\
\text { between exports to different } \\
\text { countries }\end{array}$ & $\begin{array}{l}\text { Hillberry and Hummels (2013) } \\
\text { and Bernard et al. (2007) }\end{array}$ \\
\hline$\rho$ & 0.35 & $\begin{array}{l}\text { Substitution elasticity between } \\
\text { inputs production function }\end{array}$ & Hertel et al. (2012) \\
\hline$\xi_{p_{m}}$ & 0.64 & $\begin{array}{l}\text { Rate of exchange rate } \\
\text { pass-through }\end{array}$ & Nakamura and Steinsson (2012) \\
\hline$c$ & 0.6 & Replacement rate & Boeters and Savard (2013) \\
\hline$d$ & 0.05 & Discount rate workers & Boeters and Savard (2013) \\
\hline$\varepsilon_{\frac{w}{p_{q}}, u}$ & -0.1 & Wage curve elasticity & Blanchflower and Oswald (1995) \\
\hline$\chi$ & 18 & Detection rate of shirking & Boeters and Savard (2013) \\
\hline$s$ & 0.2 & Separation rate & Boeters and Savard (2013) \\
\hline
\end{tabular}

In choosing $\rho$, the substitution elasticity between inputs in the production function, we observe that most computable general equilibrium (CGE) models work with a nested production function with a different substitution elasticity between value added and intermediates and between the different factor inputs in value added. Hertel et al. (2012) specify a Leontief structure for substitution between value added and intermediates and an elasticity between factor inputs ranging between 0.20 and 1.68. Based upon this source, we set $\rho$ at an average of 0.35 . The rate of exchange rate pass-through is set at 0.64 following recent work by Nakamura and Steinsson (2012), who employ US microdata and account for the large share of goods that are replaced.

Turning to the labor market, we follow Boeters and Savard (2013) in choosing the parameters. They argue that plausible values for $s$ and $d$ are respectively 0.2 and 0.05 . The replacement rate is set at 0.6 and the baseline unemployment rates are from the ILO. Defining the wage curve elasticity $\varepsilon_{\frac{w}{p_{q}}, u}$ as the elasticity of the wage with respect to unemployment, $\chi$ can be determined from the no shirking condition in equation (15). Boeters and Savard (2013) propose a value of -0.1 for $\varepsilon_{\frac{w}{p_{q}}, u}$ based upon

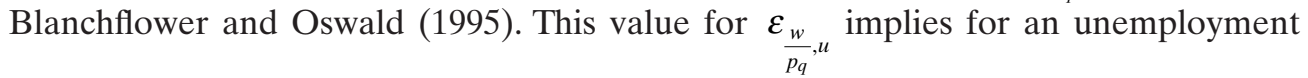
rate of 0.05 a $\chi$ close to 18 . Finally, the effort level $e$ follows from the baseline values of the other parameter values and the baseline unemployment rate. Explicit expressions for both $\chi$ and $e$ are derived in the Appendix. We abstract from imperfect information on the labor market in the simulations.

Before pointing out the results of the numerical analysis, we briefly discuss expected changes in the effect of revaluation of one of the country's trading partners moving from a small economy model to a setting with multiple, large countries. The 
first is that foreign prices $\pi_{m, i}$ and $\pi_{e, i}$ vary in a large country setting with the volume of the country's imports and exports. The revaluation raises both the export and import price in domestic currency. This implies more exports and less imports. More exports means more imports for the trading partner and a move along its import demand function, such that the export price of the home country will increase less as a result of the revaluation and the gains on the export side will be smaller. The decrease in imports means a shift along the export supply curve of the trading partner towards lower prices. Home's import price will go up less and the losses on the import side will be smaller. So, we can expect that working with a large instead of small country attenuates the effects of an exchange rate realignment.

Additionally, in the basic model we were able to focus strictly on price changes of the realigning trading partner. If the realigning country also revalues relative to third countries, export and import prices vis-à-vis other countries will change as well. This will magnify effects. Revaluation of the realigning trading partner vis-à-vis other countries implies on the export side that home becomes cheaper in third markets and will pick up market share. Exports and the export price will increase implying larger gains on the export side. On the import side, effects also become larger. Third countries will have to pay more for imports from the revaluing country. This drives up their price of exports through increased prices of intermediates and a shift in demand towards nontradables. The higher export price of third countries makes imports for our country more expensive with adverse unemployment effects. So, both the beneficial effect on the export side and the adverse effect on the import side become larger in a multicountry setting.

Hence, on net we do not know what the effects are. Working with a large country attenuates effects, whereas the multiple country setting magnifies effects.

We numerically evaluate the effects of revaluation by China on the unemployment rate in the USA, starting from the baseline for 2007. We implement both a $20 \%$ revaluation against the USA (a bilateral revaluation), and a 20\% revaluation against the world (a multilateral revaluation). This is done while ranging parameters to examine their role.

In the top panel of Figure 1 we display the baseline unemployment rate of $4.6 \%$ in the USA and the unemployment rate in the USA after a $20 \%$ bilateral and multilateral revaluation by China as a function of the rate of exchange rate pass-through $\xi_{p_{m}}$. The figure shows that the unemployment rate can both rise and fall in response to Chinese revaluation, depending upon the rate of exchange rate pass-through. The bottom panel of Figure 1 exposes the baseline trade deficit of the USA (in US\$10,000) and the trade deficit after bilateral and multilateral revaluation. The top and bottom panel make clear that a rising or falling unemployment rate can go along with an improving trade balance (a lower trade deficit) depending upon the degree of exchange rate pass-through. Hence, we can make the following observation:

OBSERVATION 1. In a multi-country setting with large countries, revaluation of the currency of one of the trading partners can lead to both a fall and a rise in the unemployment rate, even with an improvement in the trade balance.

Next, we evaluate how the different parameters affect the unemployment impact of bilateral revaluation. In all figures the baseline unemployment rate in the USA is $4.6 \%$ and the values of the parameters not varied are as in Table 1. In Figure 2 we explore how the US unemployment rate change in response to Chinese multilateral revaluation is a function of both the exchange rate pass-through $\xi_{p_{m}}$ and the wage 


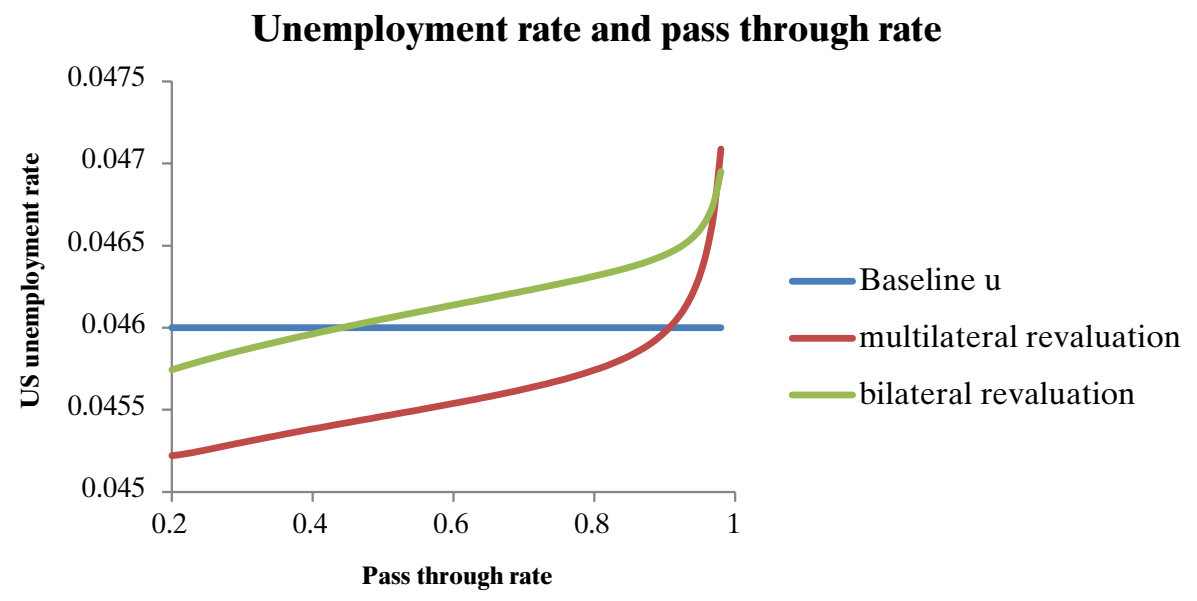

Trade deficit and pass through rate

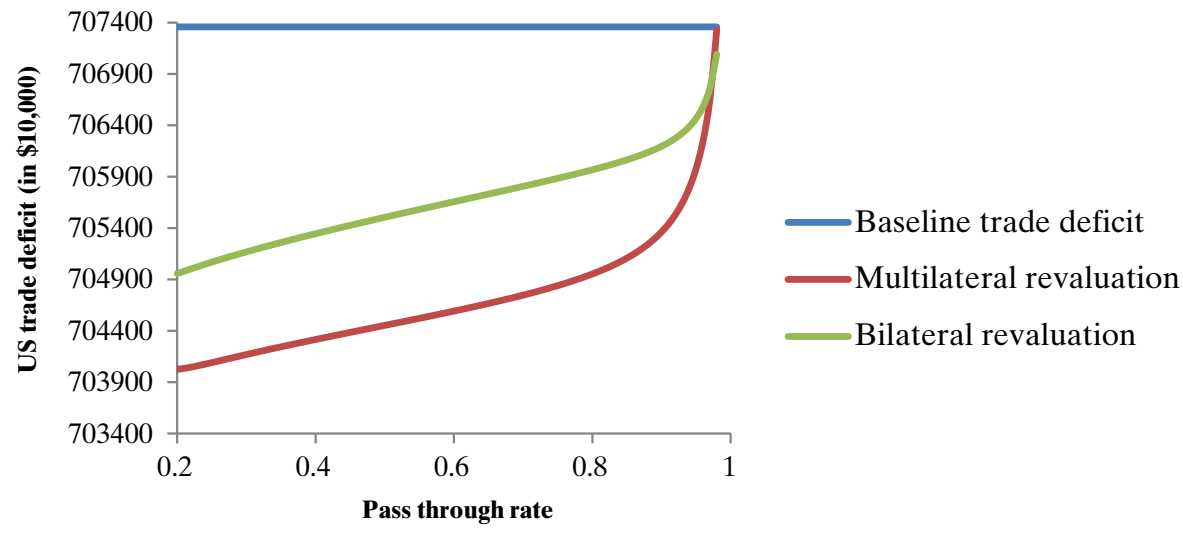

Figure 1. The Effect of a 20\% Chinese Multilateral Revaluation on the US Unemployment Rate and the US Trade Deficit as a Function of the Pass-through Rate

curve elasticity $\varepsilon_{\frac{w}{p_{q}}, u}$. Figure 3 displays the change in the unemployment rate with Chinese multilateral revaluation as a function of the pass-through rate $\xi_{p_{m}}$ and the substitution elasticity between input factors, $\rho$. Finally, Figure 4 shows the unemployment rate change after Chinese multilateral revaluation as a function of the import demand substitution elasticity between varieties from different countries $\eta$ and the elasticity of transformation between exports to different destinations, $\omega$. Based upon these three figures we make the following observation:

OBSERVATION 2. In a multi-country setting with large countries, the effect of Chinese revaluation on the US unemployment rate

(1) is more likely to be positive with a larger degree of exchange rate pass-through;

(2) gets magnified with a smaller wage curve elasticity;

(3) gets magnified with a larger input substitution elasticity;

(4) can be both more and less likely with a larger import substitution elasticity;

(5) can be both more and less likely with a larger export transformation elasticity. 


\section{Unemployment rate, wage curve elasticity and pass through rate}

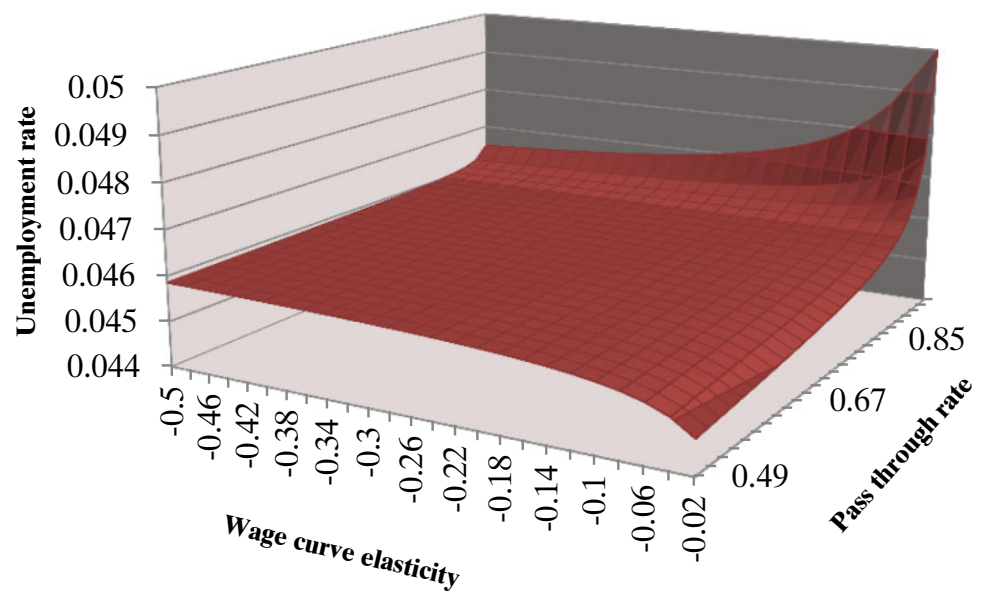

Figure 2. The Effect of a $20 \%$ Chinese Multilateral Revaluation on the US Unemployment Rate as a Function of the Pass-through Rate and Wage Curve Elasticity

\section{Unemployment rate, input substitution elasticity and pass through} rate

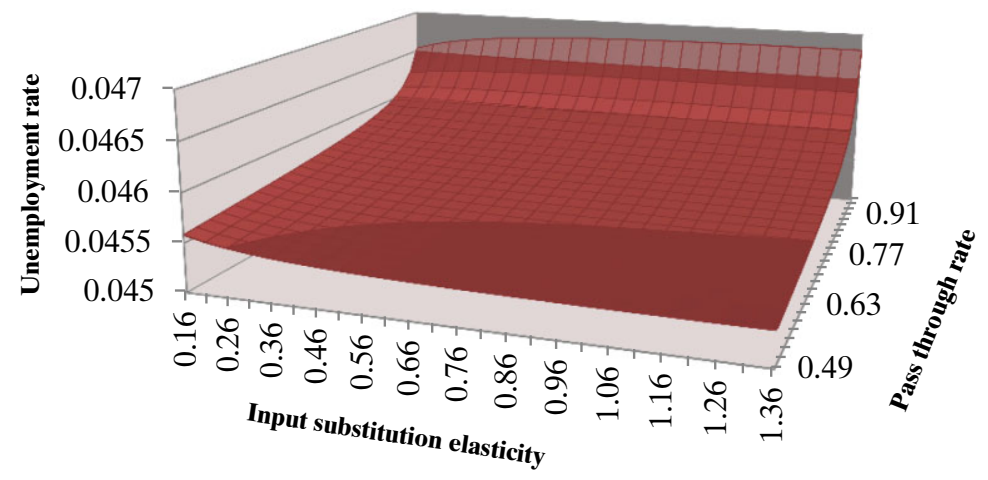

Figure 3. The Effect of a $20 \%$ Chinese Multilateral Revaluation on the US Unemployment Rate as a Function of the Pass-through Rate and the Input Substitution Elasticity

Part (1) of Observation 2 follows from Figures 1-3. A larger degree of exchange rate pass-through raises the adverse impact on unemployment on the import side. Therefore, it is more likely that unemployment in the USA will rise as a result of Chinese revaluation. ${ }^{16}$ Part (2) follows from Figure 2. If the unemployment rate falls below the baseline of $4.6 \%$ as a result of Chinese revaluation, the unemployment rate falls more with a smaller wage curve elasticity. If the unemployment rate rises above $4.6 \%$, it rises more with a smaller wage curve elasticity. The sign of the impact on the unemployment rate is determined by the net effects on labor demand and the size of the wage curve elasticity then determines the size of the reaction.

Figure 3 leads to part (3) of Observation 2. If the unemployment rate rises above $4.6 \%$, the increase is stronger with a larger input substitution elasticity and if it falls 


\section{Unemployment rate, import substitution and export transformation elasticity}

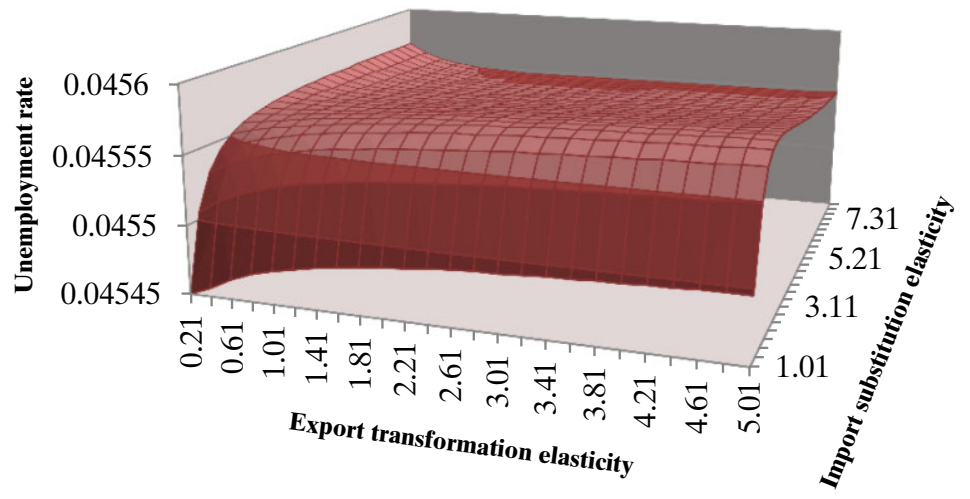

Figure 4. The Effect of a 20\% Chinese Multilateral Revaluation on the US Unemployment Rate as a Function of the Import Sustitution Elasticity and the Export Transformation Elasticity

the unemployment rate drops more with a larger input substitution elasticity. The input substitution elasticity affects the unemployment response to bilateral revaluation through two channels. First, revaluation of a trading partner makes imported intermediates more expensive leading to a substitution from intermediates towards labor in production. This substitution is stronger with a larger input substitution elasticity and this leads to a larger drop in the unemployment rate. Second, revaluation raises the price of final goods imported and this drives up wage demand and thereby raises the unemployment rate. This increasing impact on the unemployment rate is stronger with a larger input substitution elasticity, as there will be more substitution away from labor. With a falling unemployment rate, the first effect dominates and with a rising unemployment rate, the second effect dominates.

Part (4) and (5) follow from Figure 4. So, the impact of the import substitution elasticity $\eta$ and the export transformation elasticity $\omega$ on the reduction in the US unemployment rate as a result of Chinese revaluation is ambiguous. The intuition for the ambiguous effects is somewhat complicated. The import substitution elasticity affects the US unemployment rate response in two ways. First, the unemployment rate falls more as a result of Chinese revaluation with a larger substitution elasticity, because the USA can more easily shift import demand away from Chinese goods towards goods from other countries. Figure 4 makes clear that this effect dominates for larger values of $\eta$. Second, a larger substitution elasticity means that third countries can switch more easily between sourcing countries. This is bad for the demand for US products, since the USA becomes more expensive relative to other sourcing countries as a result of Chinese revaluation with the USA importing a relatively large amount from China. This effect dominates for small values of $\eta$.

The export transformation elasticity also affects the Chinese revaluation impact on US unemployment in two ways. First, a larger export transformation elasticity means that third countries can transfer their exports more easily from China towards the US market. This leads to a larger drop in the US unemployment rate, because the USA benefits from the easier transformation of third countries through reduced import prices. From Figure 4 this effect dominates for larger values of the import substitution 
elasticity $\eta$. Second, a larger transformation elasticity makes it easier for both the USA and third countries to shift exports away from other third countries towards China. Since the USA is relatively expensive because of its share of imports from China, third countries benefit more from easier transformation of goods destined for the Chinese market. For low values of $\eta$ this effect dominates and the US unemployment rate falls less with a higher transformation elasticity. ${ }^{17}$

\section{Summary and Closing Remarks}

In this paper we have examined the real-side impacts of bilateral exchange rate pegs, undervaluation, and revaluation (like China's peg to the US dollar). We have used the open economy model of de Melo and Robinson (1989), adding intermediate linkages and variable labor market conditions, to study the unemployment effects of bilateral revaluation. In deviation from the existing literature we focused on the unemployment effects of bilateral rather than general revaluation.

We employed a small open economy version of the model to derive a set of analytical results and used numerics to study a large multicountry setting. In the small open economy version of the model we demonstrated analytically that under fully flexible labor markets and full pass-through, unemployment falls with revaluation of one of the trading partners' currency when the fraction exported to the trading partner is larger than the fraction imported. In the numerical large country version of the model, we showed that Chinese revaluation both vis-à-vis the dollar only and vis-à-vis all other currencies can generate both a positive and negative unemployment effects. Adverse unemployment effects can go along with an improving trade balance. The numerics illuminated moreover the effect of the different model parameters on the unemployment effects of Chinese revaluation.

Our focus here has been on the real-side impact of undervaluation, e.g. the direct unemployment effects of exchange rate realignment linked to relative price changesrather than the issue of sustainability of current account imbalances. In the current context of both China (vis-à-vis the USA) and Germany (vis-à-vis the euro zone), this provides unemployment-related insight into the political economy of exchange rate policy. With respect to the framework explored here, extensions that combine real misalignment with a sub-set of countries (like within the euro) might be particularly fruitful.

\section{Appendix}

\section{Derivations Small Open Economy Model}

In this appendix we derive the effect of a change in the exchange rate $R_{i}$ on unemployment $u$ in the analytically tractable small economy model starting from trade balance. We derive the effect first in the baseline model without rigidities and then in the model with labor market rigidities and incomplete pass-through.

Baseline model In the baseline model we log differentiate both the supply side and the demand side. We start by log differentiating the supply side of the economy, equations (13)-(16):

$$
\begin{aligned}
& \hat{X}=\lambda_{I} \hat{I}+\lambda_{L} \hat{L}, \\
& \hat{I}=\rho\left(\widehat{p_{x}}-\widehat{p_{q}}\right)+\hat{X},
\end{aligned}
$$




$$
\begin{aligned}
& \hat{L}=\rho\left(\widehat{p_{x}}-\hat{w}\right)+\hat{X}, \\
& \hat{w}=\widehat{p_{q}}-\frac{\frac{s}{u}}{\delta+\chi+\frac{s}{u}} \hat{u}, \\
& \hat{L}=-\frac{u}{1-u} \hat{u} .
\end{aligned}
$$

Substituting (A2) and (A5) into (A1) gives:

$$
\hat{X}=\frac{\lambda_{I}}{1-\lambda_{I}} \rho\left(\widehat{p_{x}}-\widehat{p_{q}}\right)-\frac{\lambda_{L}}{1-\lambda_{I}} \frac{u}{1-u} \hat{u}
$$

Substituting (A5) and (A6) into (A3) leads to:

$$
\frac{u}{1-u} \hat{u}=-\rho \frac{1}{1-\lambda_{I}-\lambda_{L}} \widehat{p_{x}}+\rho \frac{1-\lambda_{I}}{1-\lambda_{I}-\lambda_{L}} \hat{w}+\rho \frac{\lambda_{I}}{1-\lambda_{I}-\lambda_{L}} \widehat{p_{q}} .
$$

The last step in log differentiating the supply side is to substitute (A4) into (A7) to solve for the relative change in $u$ as a function of the relative change in $p_{x}$ and $p_{q}$ :

$$
\hat{u}=\frac{\rho}{A(u)} \frac{1}{1-\lambda_{I}-\lambda_{L}}\left(\widehat{p_{q}}-\widehat{p_{x}}\right)
$$

$A(u)$ is defined as:

$$
A(u)=\frac{u}{1-u}+\rho \frac{1-\lambda_{I}}{1-\lambda_{I}-\lambda_{L}} \frac{\frac{s}{u}}{d+\chi+\frac{s}{u}} .
$$

Next, we turn to the demand side. The relative change in $p_{q}$ and $p_{x}$ is derived as a function of the relative change in the exchange rate $R_{i}$. We start with log differentiation of (3) and (4):

$$
\begin{aligned}
& \widehat{p_{q}}=\kappa_{T R} \widehat{p_{m}}+\left(1-\kappa_{T R}\right) \widehat{p_{d}}, \\
& \widehat{p_{x}}=\kappa_{T R} \widehat{p_{e}}+\left(1-\kappa_{T R}\right) \widehat{p_{d}} .
\end{aligned}
$$

$\kappa_{T R}$ is the trade share of output, $\kappa_{T R}=\frac{p_{e} E}{p_{e} E+p_{d} D}$ and is equal on the import and export side. So, we work with the assumption that the economy starts from balanced trade, $B=0$.

Log differentiating (10) and (11) and substituting the result into the log differentiation of (8) and (9) gives:

$$
\widehat{p_{m}}=s_{m, i} \widehat{R_{i}},
$$




$$
\widehat{p_{e}}=s_{e, i} \widehat{R_{i}}
$$

Substituting (A12) and (A13) into (A10)-(A11) gives:

$$
\widehat{p_{q}}-\widehat{p_{x}}=\kappa_{T R}\left(s_{m, i}-s_{e, i}\right) \widehat{R_{i}} \text {. }
$$

Finally, the demand and supply side are combined and (A14) is substituted into (A8) to get the expression for the relative change in unemployment as a function of the exchange rate realignment of one of the trading partners in equation (18) in the main text:

$$
\hat{u}=\frac{\rho}{A(u)} \frac{1}{1-\lambda_{I}-\lambda_{L}} \kappa_{T R}\left(s_{m, i}-s_{e, i}\right) \widehat{R}_{i}
$$

Model with rigidities Next, we move to the extended model with rigidities. As pointed out in the main text, labor market rigidities are modeled with imperfect information among workers about changes in price levels. The no shirking condition in (15) is changed into:

$$
\frac{w}{p_{q}^{e}}=\frac{1}{1-c}\left(d+\chi+\frac{s}{u}\right) \frac{e}{\chi} .
$$

The relative change in the expected price level expresses imperfect information among workers:

$$
\widehat{p_{q}^{e}}=\xi_{p_{q}} \widehat{p_{q}}
$$

where $\xi_{p_{q}}$ is an inverse measure for the degree of imperfect information. If $\xi_{p_{q}}=0$ the expected price level does not respond to actual changes in the price level and if $\xi_{p_{q}}=1$ the expected price level responds fully to actual price level changes.

Incomplete pass-through means that the domestic import price $p_{m, i}$ reacts less than proportional to changes in the exchange rate $R_{i}$ :

$$
\widehat{p_{m, i}}=\xi_{p_{m, i}} \widehat{R_{i}}
$$

$\xi_{p_{m, i}}$ is a measure for the degree of exchange rate pass-through of goods from country $i$.

We can again derive the unemployment effect of exchange rate realignment of a trading partner by log differentiating the supply side and the demand side. On the supply side only the log differentiation of the no shirking condition changes and becomes:

$$
\hat{w}=\xi_{p_{q}} \widehat{p_{q}}-\frac{\frac{s}{u}}{d+\chi+\frac{s}{u}} \hat{u} .
$$

Combining (A19) with the equations in the baseline model, (A1)-(A3) and (A5) and going through the same sequence of steps leads to the following expression for the relative change in $u$ as a function of the relative change in $p_{q}$ and $p_{x}$ : 


$$
\hat{u}=\frac{\rho}{A(u)} \frac{1}{1-\lambda_{I}-\lambda_{L}}\left(\left(\lambda_{I}+\xi_{p_{q}}\left(1-\lambda_{I}\right)\right) \widehat{p_{q}}-\widehat{p_{x}}\right) .
$$

Next, we turn to the demand side to derive $\widehat{p_{q}}$ and $\widehat{p_{x}}$. The change in the import price $p_{m}$ and the export price $p_{e}$ can be expressed as follows from equations (8), (9), (11) and (A18):

$$
\begin{aligned}
& \widehat{p_{m}}=s_{m, i} \xi_{p_{m, i}} \widehat{R_{i}}, \\
& \widehat{p_{e}}=s_{e, i} \widehat{R_{i}} .
\end{aligned}
$$

The change in the consumer price $p_{q}$ and the consumer price $p_{x}$ follow from substituting equations (A21)-(A22) into (A10)-(A11):

$$
\begin{aligned}
& \widehat{p_{q}}=\kappa_{T R} s_{m, i} \xi_{p_{m, i}} \widehat{R_{i}}+\left(1-\kappa_{T R}\right) \widehat{p_{d}}, \\
& \widehat{p_{x}}=\kappa_{T R} s_{e, i} \widehat{R_{i}}+\left(1-\kappa_{T R}\right) \widehat{p_{d}} .
\end{aligned}
$$

Log differentiating equations (6) and (5), using (A21) and (A22):

$$
\begin{aligned}
& s_{m, i} \widehat{M_{i}}-\hat{D}=\sigma\left(\widehat{p_{d}}-s_{m, i} \xi_{p_{m, i}} \widehat{R_{i}}\right), \\
& s_{e, i} \widehat{E_{i}}-\hat{D}=\theta\left(s_{e, i} \widehat{R_{i}}-\widehat{p_{d}}\right) .
\end{aligned}
$$

Combining (A25) and (A26) leads to:

$$
s_{e, i} \widehat{E_{i}}-s_{m, i} \widehat{M_{i}}=\left(\theta s_{e, i}+\sigma s_{m, i} \xi_{p m, i}\right) \widehat{R_{i}}-(\theta+\sigma) \widehat{p_{d}} .
$$

Log differentiating the Balance of Payments condition, equation (12), using (A21) and (A22), gives:

$$
d B=s_{m, i}\left(\widehat{M}_{i}+\widehat{R}_{i}\right)-s_{e, i}\left(\widehat{E}_{i}+\xi_{p_{m, i}} \widehat{R_{i}}\right) .
$$

Substituting equation (A27) into (A28) implies the following equation for the relative change of $p_{d}$ :

$$
\widehat{p_{d}}=\frac{\left((\theta+1) s_{e, i}+s_{m, i} \xi_{p m, i}(\sigma-1)\right) \widehat{R_{i}}}{\theta+\sigma}+\frac{1}{\theta+\sigma} d B .
$$

The final step is to substitute (A29) into (A23)-(A24) and to substitute the result into (A20). This generates equation (19) in the main text with $A_{2}$ defined as follows:

$$
A_{2}=\frac{(\theta+1) s_{e, i}+(\sigma-1) s_{m, i} \xi_{p_{m, i}}}{\theta+\sigma} .
$$

In the discussion in section 3 of the main text we have abstracted from the effects of a changing trade balance and thus neglected the term $d B$ in equation (19). To keep the model analytically tractable as motivated in the introduction, we abstract from trade in financial assets and simply distinguish between two cases: one where the 
Marshall-Lerner condition is not and one where it is satisfied. These correspond empirically with the short run and medium run, respectively. When the MarshallLerner condition is not satisfied, $d B / d R_{i}>0$, i.e. the trade balance deteriorates with revaluation of a country's trading partner. From equation (19), we see that the employment effect of the deteriorating trade balance is positive. If more capital flows into the country, i.e. $d B>0$, the demand for labor will increase through an increase in the price of nontradables. When the Marshall-Lerner condition is satisfied, the trade balance improves. This raises unemployment, because the demand for labor declines as a result of the declining price of nontradables. Dynamic effects of an improving trade balance like capital outflows leading to less demand for labor are not taken into account.

\section{The Numerical Model}

The numerical model is described by the following set of equations. Variables with a subscript $i j$ indicate flows from country $i$ to country $j$.

$$
\begin{aligned}
& X_{i}=G_{i}\left(E_{i}, D_{s, i}\right)=\left(\beta_{E_{i}} E_{i}^{\frac{\theta+1}{\theta}}+\beta_{D_{s, i}} D_{s, i}^{\frac{\theta+1}{\theta}}\right)^{\frac{\theta}{\theta+1}} \\
& Q_{i}=F_{i}\left(M_{i}, D_{d, i}\right)=\left(\alpha_{M_{i}} M_{i}^{\frac{\sigma-1}{\sigma}}+\alpha_{D_{d, i}} D_{d, i}^{\frac{\sigma-1}{\sigma}}\right)^{\frac{\sigma}{\sigma-1}} \\
& M_{j i}=\left(\frac{p_{m_{j i}}}{\gamma_{j i} p_{m_{i}}}\right)^{-\eta} M_{i} \\
& E_{i j}=\left(\frac{p_{e_{i j}}}{\delta_{i j} p_{e_{i}}}\right)^{\omega} E_{i} \\
& p_{q_{i}}=\left(\alpha_{M_{i}}^{\sigma} p_{m_{i}}^{1-\sigma}+\alpha_{D_{d, i}}^{\sigma} p_{d_{i}}^{1-\sigma}\right)^{\frac{1}{1-\sigma}} \\
& p_{x_{i}}=\left(\beta_{E_{i}}^{-\theta} p_{e_{i}}^{\theta+1}+\beta_{D_{s, i}}^{-\theta} p_{d_{i}}^{\theta+1}\right)^{\frac{1}{\theta+1}} \\
& E_{i j}=M_{i j}=\left(\sum_{j \neq i}^{N} \delta_{i j}^{-\omega} p_{e_{i j}}^{\omega+1}\right)^{\frac{1}{\omega+1}} \\
& p_{m_{i}}=\left(\sum_{j \neq i}^{N} \gamma_{j i j}^{\eta} p_{m_{j i}}^{1-\eta}\right)^{\frac{1}{1-\eta}}
\end{aligned}
$$




$$
\begin{aligned}
& \frac{M_{i}}{D_{d, i}}=\left(\frac{\alpha_{M_{i}}}{\alpha_{D_{d, i}}} \frac{p_{d_{i}}}{p_{m_{i}}}\right)^{\sigma} \\
& \frac{E_{i}}{D_{s, i}}=\left(\frac{\beta_{D_{s, i}}}{\beta_{E_{i}}} \frac{p_{e_{i}}}{p_{d_{i}}}\right)^{\theta} \\
& B_{i}=p_{m_{i}} M_{i}-p_{e_{i}} E_{i} \\
& B_{i}=\bar{B} \\
& D_{d_{i}}-D_{s_{i}}=0 \\
& X_{i}=\left(\phi_{I_{i}} I_{i}^{\frac{\rho-1}{\rho}}+\phi_{L_{i}} L_{i}^{\frac{\rho-1}{\rho}}+\phi_{K_{i}} K_{i}^{\frac{\rho-1}{\rho}}\right)^{\frac{\rho}{\rho-1}} \\
& I_{i}=\left(\phi_{I_{i}} \frac{p_{x_{i}}}{p_{q_{i}}}\right)^{\rho} X_{i} \\
& L_{i}=\left(\phi_{L_{i}} \frac{p_{x_{i}}}{w_{i}}\right)^{\rho} X_{i} \\
& w_{i}=\frac{p_{q_{i}}^{e}}{1-c}\left(\delta+\chi_{i}+\frac{s}{u_{i}}\right) \frac{e_{i}}{\chi_{i}} \\
& L_{i}=\left(1-u_{i}\right) \overline{L_{i}} \text {. }
\end{aligned}
$$

$R_{i j}$ is the exchange rate between country $i$ and $j$ or more specifically the price of the currency of country $i$ expressed in terms of the currency of country $j$. So, an increase in $R_{i j}$ reflects revaluation of the currency of country $i$ relative to the currency of country $j$.

All the equations are as in the small economy model. We added equations for import demand and export supply per country (A33) and (A34) and an equation imposing that the exports of country $i$ to country $j$ are equal to the imports of country $j$ from country $i$.

We get $16 N+4(N-1) N$ equations in the same number of unknowns, the following 16 variables per country:

$$
X_{i}, Q_{i}, M_{i}, E_{i}, D_{d_{i}}, D_{s_{i}}, p_{x_{i}}, p_{q_{i}}, p_{d_{i}}, p_{e_{i}}, p_{m_{i}}, B_{i}, I_{i}, L_{i}, u_{i}, w_{i}
$$

and the $N-1$ variables $M_{i j}, E_{i j}, p_{m_{i j}}, p_{e_{i j}}$ per country.

Running experiments, we add two sets of equations for sticky prices and wages. Incomplete adjustment of the price expectations in wage formation implies:

$$
\widehat{p_{q_{i}}^{e}}=\xi_{p_{q_{i}}} \widehat{p_{q_{i}}}
$$

Incomplete pass-through implies: 


$$
\widehat{p_{m_{i j}}}=\xi_{p_{i j}}\left(\widehat{R_{i j}}+\widehat{p_{e_{i j}}}\right) \text {. }
$$

To model changes in the trade balance, we distinguish between the cases where the Marshall Lerner condition is and is not satisfied. We work with the following equation for the changing trade balance:

$$
\widehat{B_{i j}}=\mu \operatorname{sign}\left(B_{i j}\right) \widehat{R_{i j}}
$$

where $\mu>0$ and $\mu<0$ reflect respectively the situations where the Marshall-Lerner is and is not satisfied. If the initial capital balance is positive $\left(B_{i j}>0\right)$ and $\mu>0$, revaluation of the currency of country $i$ relative to country $j$ raises $B_{i j}$, so increases capital inflows into the country. If the initial capital balance is negative and $\mu>0$, revaluation of the currency of country $i$ relative to country $j$ should raise $B_{i j}$ as well and so should decrease $B_{i j}$ in absolute terms. Therefore, we have to add the $\operatorname{sign}\left(B_{i j}\right)$ term.

The change in the total trade balance is a function of the sum of the bilateral trade balance changes:

$$
\begin{aligned}
\widehat{B_{i}} & =\sum_{j \neq i} \frac{B_{i j}}{B_{i}} \widehat{B_{i j}} \\
& =\sum_{j \neq i} \frac{B_{i j}}{B_{i}} \mu \operatorname{sign}\left(B_{i j}\right) \widehat{R_{i j}} .
\end{aligned}
$$

Next, we turn to the calibration of the labor market. The wage curve elasticity $\varepsilon_{\frac{w}{p q}}, u$ can be calculated easily from equation (15):

$$
\varepsilon_{\frac{w}{p q}, u}=-\frac{\frac{s}{u_{i}}}{d+\chi+\frac{s}{u_{i}}} .
$$

Equation (A55) can be solved for $\chi$ :

$$
\chi_{i}=-\frac{s}{u_{i}}\left(1+\frac{1}{\frac{\varepsilon_{w}}{p_{q}, u}}\right)-d .
$$

Finally, the effort level follows from labor market equilibrium and setting the values of the different variables at their baseline level. Labor market equilibrium requires:

$$
\phi_{L_{i}} p_{x_{i}}\left(\frac{X_{i}}{L_{i}}\right)^{\frac{1}{\rho}}=\frac{1}{1-c}\left(d+\chi_{i}+\frac{s}{u_{i}}\right) \frac{e_{i} p_{q_{i}}}{\chi_{i}} .
$$

Solving for $e$ gives:

$$
e_{i}=\frac{\phi_{L_{i}}\left(\frac{X_{i}}{L_{i}}\right)^{\frac{1}{\rho}}}{\frac{1}{1-c}\left(d+\chi_{i}+\frac{s}{u_{i}}\right) \frac{1}{\chi_{i}}} \frac{p_{x}}{p_{q}} .
$$


Table A1. List of Variables and Parameters

\begin{tabular}{ll}
\hline Variable & \\
\hline$X$ & gross output \\
$Q$ & gross demand \\
$M, E$ & imports and exports \\
$p_{q}, p_{x}$ & price of demand and output \\
$p_{m}, p_{e}$ & price of imports and exports \\
$p_{m, i}, p_{e, i}$ & home price of imports and exports of country $i$ \\
$R_{i}$ & nominal exchange rate between home and country $i$ \\
$\pi_{m, i}, \pi_{e, i}$ & country $i$ price of imports and exports \\
$B$ & net capital inflow into home, measured in domestic prices \\
$D_{d}, D_{s}$ & demand and supply of non tradable \\
$I, L, K$ & intermediates, employment and capital \\
$u$ & unemployment rate \\
$w$ & (nominal) wage \\
\hline Parameters & \\
\hline$\sigma$ & \\
$\eta$ & elasticity of substitution between domestic goods and imports \\
$\theta$ & elasticity of substitution between imports from different countries \\
$\omega$ & elasticity of transformation between domestic goods and exports \\
$\rho$ & elasticity of transformation between exports to different countries \\
$d$ & elasticity of substitition between inputs in production function \\
$s, \chi$ & discount rate of workers \\
$e$ & separation rate of workers and detection rate of shirking \\
$c$ & effort level in case of no shirking \\
$\beta_{E}, \beta_{D_{s}}$ & replacement rate \\
$\alpha_{M}, \alpha_{D_{d}}$ & shift parameters in supply of exports and domestic goods \\
$\gamma_{i}, \delta_{i}$ & shift parameters in demand for imports and domestic goods \\
$\phi_{I}, \phi_{L}, \phi_{K}$ & shift parameters in imports from and exports to different trade partners \\
$\xi_{q}$ & shift parameters in production function \\
$\xi_{p m, i}$ & degree of stickyness of price expectations \\
\hline &
\end{tabular}

\section{References}

Adolfson, Malin, Stefan Laseen, Jesper Linde, and Mattias Villani, "Bayesian Estimation of an Open Economy DSGE Model with Incomplete Pass-through," Journal of International Economics 72 (2007):481-511.

Bebczuk, Ricardo, Arturo Galindo, and Ugo Panizza, "An Evaluation of the Contractionary Devaluation Hypothesis," Inter-American Development Bank, Research Department working paper 582 (2006).

Bergsten, C. F., "Correcting the Chinese Exchange Rate: An Action Plan," in S. Evenett (ed.), The US-Sino Currency Dispute: New Insights from Economics, Politics and Law, London: CEPR (2010).

Bernard, Andrew B., Stephen J. Redding, and Peter K. Schott, "Comparative Advantage and Heterogeneous Firms," Review of Economic Studies 74 (2007):31-66.

Blanchflower, D. G. and A. J. Oswald, The Wage Curve, Cambridge, MA: MIT Press (1995).

Bodenstein, M., C. J. Erceg, and L. Guerrieri, "The Effects of Foreign Shocks when Interest Rates are at Zero," Federal Reserve International Finance discussion papers 983. (2009). 
Boeters, Stefan and Luc Savard, "The Labor Market in Computable General Equilibrium Models," in Peter Dixon and Dale Jorgeson (eds), Handbook of CGE Modelling, vol. 1A, Amsterdam: Elsevier (2013).

Campbell, Carl M., "Deriving the Wage-Wage and Price-Price Philips Curves from a Model with Efficiency Wages and Imperfect Information," Economics Letters 107 (2010):242-5.

Cespedes, L. F., R. Chang, and A. Velasco, "Balance Sheets and Exchange Rate Policy," American Economic Review 94 (2004):1183-93.

de Melo, Jaime and Sherman Robinson, "Product Differentiation and the Treatment of Foreign Trade in Computable General Equilibrium Models of Small Economies," Journal of International Economics 27 (1989):47-67.

Diaz-Alejandro, "A Note on the Impact of Devaluation and Distributive Effects," Journal of Political Economy 71 (1963):577-80.

Edwards, S., "Are Devaluations Contractionary?" Review of Economics and Statistics 68 (1986):501-8.

Erceg, C. J., L. Guerrieri, and C. Gust, "SIGMA: A New Open Economy Model for Policy Analysis," International Journal of Central Banking 2 (2006):1-50.

Evenett, S., The US-Sino Currency Dispute: New Insights from Economics, Politics and Law. London: CEPR (2010).

Fair, R. C., "Estimated Macroeconomic Effects of a Chinse Yuan Appreciation," Business Economics 45 (2010):233-43.

Feenstra, Robert, "Measuring the Gains from Trade under Monopolistic Competition," Canadian Journal of Economics 43 (2010):1-28.

Feenstra, R. C., M. Obstfeld and K. N. Russ, "In Search of the Armington Elasticity," University of California-Davis, unpublished mimeo (2012).

Francois, Joseph F. and Reinert, Kenneth A. (eds), Applied Methods for Trade Policy Analysis, Cambridge: Cambridge University Press (1998).

Frankel, J. A., "Contractionary Currency Crises in Developing Countries," IMF Staff Papers 52 (2005):149-92.

— , "Monetary Policy in Emerging Markets: A Survey," in Benjamin Friedman and Michael Woodford (eds), Handbook of Monetary Economics. Amsterdam: Elsevier (2011).

Gali, Jordi and Tommaso Monacelli, "Monetary Policy and Exchange Rate Volatility in a Small Open Economy," Review of Economic Studies 72 (2005):707-34.

Goldstein, M. and N. Lardy, "China's Exchange Rate Policy Dilemma," The American Economic Review 96 (2006):422-6.

Gopinath, Gita and Roberto Rigobon, "Sticky Borders," Quarterly Journal of Economics 123 (2008):531-75.

Gylfason, T. and M. Radetzki, "Does Devaluation Make Sense in the Least Developed Countries?" Economic Development and Cultural Change 40 (1991):1-25.

Hertel, Thomas W., Narayanan G. Badri, and Robert A. McDougall, "Behavioral Parameters," in G. Narayanan, Angel Aguiar Badri, and Robert McDougall (eds), Global Trade, Assistance, and Production: The GTAP 8 Data Base, Lafayette, IN: Center for Global Trade Analysis, Purdue University (2012).

Hirschman, A. O., "Devaluation and the Trade Balance: A Note," Review of Economics and Statistics 16 (1949):50-3.

Hillberry, Russell and David Hummels, "Trade Elasticity Parameters for a CGE Model," in Peter Dixon and Dale Jorgeson (eds), Handbook of CGE Modelling, vol. 1A, Amsterdam: Elsevier (2013).

ILO, ILO Yearbook of Labor Statistics: Time Series, Geneva: ILO (2012).

IMF, IMF World Economic Outlook Database October 2010, Washington, DC: IMF (2010).

Kamin, S. B. and H. R. John, "Output and the Real Exchange Rate in Developing Countries: An Application to Mexico," Journal of Development Economics 61 (2000):85-109.

Krugman, P., "Introduction," in Paul Krugman (ed.), Trade with Japan: Has the Door Opened Wider? Chicago, IL: University of Chicago Press (1991).

—_, "Taking in China and its Currency," New York Times, 15 March 2010. 
Krugman, P. and L. Taylor, "Contractionary Effects of Devaluation," Journal of International Economics 8 (1978):445-56.

Lizondo, S. and P. J. Montiel, "Contractionary Devaluation in Developing Countries: An Analytical Overview," IMF Staff Papers 36 (1989):182-227.

Mankiw, N. Gregory and Ricardo Reis, "Sticky Information Versus Sticky Prices: A Proposal to Replace the New Keynesian Phillips Curve," The Quarterly Journal of Economics 117 (2002):1295-328.

- "Imperfect Information and Aggregate Supply," in Benjamin Friedman and Michael Woodford (eds), Handbook of Monetary Economics, vol. 3, Amsterdam: Elsevier (2010):183229.

McKibbon, R. and G. Schnabi, "China and its Dollar Exchange Rate: A Worldwide Stabilising Influence?” World Economy 35 (2013):667-93.

Melitz, Marc J., "The Impact of Trade on Intra-industry Reallocations and Aggregate Industry Productivity," Econometrica 71 (2003):1695-725.

Nakamura, E. and D. Steinsson, "Lost in Transit: Product Replacement Bias and Pricing to Market," American Economic Review 102 (2012):3277-3316.

Pissarides, C. A., "The Impact of Employment Tax Cuts on Unemployment and Wages; The Role of Unemployment Benefits and Tax Structure," European Economic Review 42 (1998):155-83.

Sato, K., J. Shimizu, N. Shrestha, and Z. Zhang, "New Estimates of the Equilibrium Exchange Rate: The Case for the Chinese Renminbi," World Economy 35 (2012):419-43.

Shapiro, C. and J. E. Stiglitz, "Equilibrium Unemployment as a Worker Discipline Device," American Economic Review 74 (1984):433-44.

Shi, Jianhuai, “Are Currency Appreciations Contractionary in China?” NBER working paper 12551 (2006).

van Wijnbergen, Sweder V., "Exchange Rate Management and Stabilization Policies in Developing Countries," Journal of Development Economics 23 (1986):227-47.

\section{Notes}

1. See for example Bergsten (2010), as well as Krugman (2010). The collection of papers in Evenett (2010) provides excellent background on the political economy relevance of bilateral currency pegs. Also see Frankel (2011) for a structural macro assessment.

2. This includes for example Sato et al. (2012) and Goldstein and Lardy (2006). As reflected in the latter, initial concern was about realignment to reflect economic reforms, which had shifted the potential trade performance of China's economy. More recent concern has included not only the jobs issue explored here, but the issue of capital account imbalances. See, for example, McKibbon and Schnabi (2013).

3. In line with this assumption money plays no role in the economy.

4. Higher import prices adversely affect employment for two reasons. Imported intermediates become more expensive, reducing the marginal product of labor and thus the demand for labor-a higher price of imported final goods leads to higher wage demands.

5. Summaries of the literature on contractionary effects of devaluations are Lizondo and Montiel (1989) and Frankel (2011). Since our focus is on bilateral revaluation, it is not likely that balance sheet effects will play a big role unless most loans are denominated in the exchange rate realigning country.

6. Table A1 in the Appendix contains a description of the variables and parameters of the model.

7. In (analytical) extensions to the basic model we relax this identity and consider incomplete pass-through.

8. Our model does not require perfectly competitive firms. Armington preferences can go along with for example small group monopolistic competition (Francois and Reinert, 1998) featuring incomplete pass-through. We do not model such a setup explicitly, though, and only explore the implications of incomplete pass-through in general. 
9. Derivation in the Appendix.

10. The term $d B$ reflecting the impact of a changing trade balance is discussed in the Appendix.

11. From equation (19) there are two channels, a direct effect through higher import prices and an indirect effect through higher prices of domestic goods when the substitution elasticity between domestic and imported varieties, $\sigma$, is larger than 1 .

12. As we are considering a small country, the rate of pass-through onto sales prices in the export market is by definition zero: firms have no market power in the foreign market and are thus not able to pass-part of the lower exchange rate onto their buyers. In the simulations we address the large country case and also come to the possibility of incomplete pass-through on the exporter side.

13. The Appendix discusses the effects of the term $d B$, representing the effect of a changing trade balance.

14. The General Algebraic Modeling System (GAMS)-based model code and the data used in the simulations are available upon request.

15. The taste parameters $\beta_{E_{i}}, \alpha_{M_{i}}, \gamma_{i j}, \delta_{i j}, \phi_{I}, \phi_{L}, \phi_{K}$ are determined by setting all prices at 1 in the baseline and expressing the taste parameters and scale parameters as a function of the value shares. Further details are available upon request. If in the baseline prices are not equal to 1 , this just means that volumes of the different variables are measured in different units.

16. The unemployment reducing effect of Chinese revaluation through more export sales by the USA is also stronger with a larger degree exchange rate pass-through. Since the USA imports much more from China than it exports to China, the effect on the import side dominates. For other countries with a different trading pattern we find reverse effects. So, for example in Australia the unemployment rate falls more with a larger degree of exchange rate pass-through, since Australia is exporting (slightly) more to China than importing from China. Simulation results are available upon request.

17. In a web Appendix we replicate Figures 2-4 for a $20 \%$ Chinese bilateral revaluation only $v i s-\grave{a}$-vis the USA and we show the effect of the remaining parameters on the impact of Chinese revaluation on the US unemployment rate. The robustness checks make clear that the effects of bilateral revaluation are similar to multilateral revaluation. Moreover, the impact of the substitution and transformation elasticity between tradables and nontradables is similar to the effect of the substitution and transformation elasticities between imports from and exports to different countries. Finally, the labor market parameters do not have any impact on the unemployment effect of Chinese revaluation.

\section{Supporting Information}

Additional Supporting Information may be found in the online version of this article at the publisher's web-site:

S1. Webappendix Derivations.

S2. Webappendix Additional Figures. 